\title{
Transmisión de infecciones nosocomiales por el personal de salud
}

\section{Transmission of nosocomial infections by health personnel}

Las infecciones nosocomiales (IN) representan un serio problema de salud a nivel global por la pérdida de vidas humanas y el impacto económico, tanto para las familias, como para el sistema hospitalario. Las tasas de infecciones nosocomiales varían entre los países, siendo mayor en los países en desarrollo (1). En Europa la tasa de IN está alrededor del 5\% y en el Perú varía entre 3,7 y 7,5\% dependiendo del tipo de institución hospitalaria (2). Las tasas de IN usualmente son mayores en las unidades de cuidados intensivos y en neonatología. Oliva-Menacho y col (3), en este número de la revista reportan una elevada contaminación de estetoscopios del personal médico con bacterias patógenas en el Hospital Nacional Arzobispo Loayza, un hospital de nivel III en Lima. Ciento once de 124 (91,9\%) estetoscopios estudiados estuvieron contaminados con bacterias patógenas, tanto Gram positivas como Gram negativas, las que con una alta frecuencia son resistentes a múltiples antibióticos. Preocupa que todos los estetoscopios excepto uno, usados por personal médico, en los servicios de pediatría (neonatología y emergencia pediátrica) estuvieron contaminados, así como, el $100 \%$ en la unidad de quemados, lo que implica un incremento del riesgo de transmisión de IN a un grupo de pacientes que de base tienen un alto riesgo. Sin embargo, este problema no es ajeno a otras instituciones; como lo refrieren los autores, estudios similares realizados en otros hospitales de nivel III muestran cifras similares de contaminación en los estetoscopios del personal médico. Así, en el Hospital Nacional Cayetano Heredia el 92,2\% de los 115 estetoscopios estudiados se encontró contaminación bacteriana (4). En la unidad de cuidados intensivos del Hospital Guillermo Almenara, el 14,8\% de las bacterias aisladas correspondió a Pseudomonas aeruginosa (5).

En la literatura médica hay irrefutables evidencias que el personal de salud es potencial transmisor de agentes patógenos a través de las manos contaminadas, ropa como mandiles, corbatas, anillos, instrumentos médicos (6) y actualmente el uso indiscriminado de celulares (7). El 42\% de los teléfonos celulares que usa el personal de salud están contaminados con baterías patógenas en comparación con $28 \%$ de los que usa el público en general (8). La diferencia con el uso de anillos es aún mayor; se ha encontrado la presencia de uno o más organismos en $82 \%$ de los anillos usados por el personal de salud versus el $36 \%$ por el público en general (9). También se ha detectado que el uso de cintas o cordones de los credenciales de identificación están contaminados (10). Evidentemente este problema trasciende solo el uso de los estetoscopios y está claramente asociado a usos y costumbres del personal de salud y donde hay que tener en cuenta las particularidades locales y regionales.

En el Perú las medidas de prevención son poco usadas. El empleo de etanol o alcohol isopropílico en la cápsula y membrana en los estetoscopios, después de examinar cada paciente, puede reducir las tasas de contaminación bacteriana en aproximadamente 92,8\% (11). Lamentablemente esta práctica no es común. El estetoscopio en los alumnos y los residentes (que son el grupo que más examina pacientes) además, es un símbolo de "status" por lo que se exhibe, incluso en los comedores. Los mandiles y ropa de uso médico ("scrubs") con frecuencia se usan tanto en las salas de hospitalización, en los ambientes de trabajo, y algunos inclusive en sus autos y casas, determinando la diseminación de bacterias multiresistentes. El uso de antisépticos en los equipos médicos tampoco es de uso frecuente, a pesar que estos consiguen disminuir la carga bacteriana significativamente (70\%). El lavado de manos es otra medida de gran importancia en la prevención de infecciones nosocomiales, pero su práctica sistemática es pobre; Arévalo y col (12), reportan que menos del 50\% del personal de salud cumplían con el adecuado lavado de manos previo a un programa de capacitación.

En este complejo problema de transmisión de infecciones nosocomiales por el personal de salud hay tres actores implicados: 1) el Ministerio de Salud que debe de ejercer su rol rector y tomar la decisión política y económica de 
proveer las facilidades técnicas e insumos para implementar de manera sistemática las medidas preventivas; 2) las instituciones formadoras de los recursos humanos en salud (universidades, escuelas e institutos), priorizando en su formación académica estos conceptos de prevención y colocando como requisito para la obtención de los títulos el cumplimiento de estas medidas de prevención y 3) el personal de salud que tiene la obligación moral y ética de cumplir con la normatividad de prevención. Solo un accionar coordinado y que sostenido (años) que permita cambios en el comportamiento del personal de salud permitirá disminuir los riesgos de infecciones nosocomiales, tanto para los pacientes como para el mismo personal de salud.

Alejandro Llanos-Cuentas $\mathrm{MD}, \mathrm{PhD}^{1, \mathrm{a}}$

\section{REFERENCIAS BIBLIOGRÁFICAS}

1. Allegranzi B, Bagheri S, Combescure C, Graafmans W, Attar H, Donaldson L, et al. Burden of endemic healthcare-associated infection in developing countries: systematic review and metaanalysis. Lancet. 2011; 377(9761):228- 41.

2. Chincha O, Cornelio E, Valverde V, Acevedo M. Infecciones intrahospitalarias asociadas a dispositivos invasivos en unidades de cuidados intensivos de un hospital nacional de Lima, Perú. Rev perú med exp Salud publica. 2013; 30(4):616620.

3. Oliva-Menacho JE, García-Hjarles MA, OlivaCandela JA, De la Cruz-Roca HS. Contaminación con bacterias patógenas de estetoscopios del personal médico en un hospital de nivel III en Lima, Perú. Rev Med Hered. 2016; 27:83-88

4. Cruz L. Prevalencia de contaminación bacteriana de los diafragmas de los estetoscopios en el Hospital Nacional Cayetano Heredia. Tesis de Bachiller Medicina. Lima, Perú: Universidad Peruana Cayetano Heredia. 1998. 33 pp.

5. Paz E, De León D, Ramírez R. Resistencia bacteriana en cuidados intensivos y tendencia actual: Departamento de Cuidados Críticos, Servicio de Cuidados Intensivos del Hospital Nacional Guillermo Almenara Irigoyen. Acta Med Per. 2008; 25(3):140-147.
6. Schabrun S, Chipchase L. Healthcare equipment as a source of nosocomial infection: a systematic review. J Hosp Infect. 2006; 63(3):239-45.

7. Baptista-González HA, Zamorano-Jiménez CA. Estetoscopio, bata y corbata, y el riesgo de infecciones nosocomiales. Rev Invest Med Sur Mex. 2011; 18(4): 195-202.

8. Tekerekoglu MS, Duman Y, Serindag A, et al. Do mobile phones of patients, companions and visitors carry multidrug-resistant hospital pathogens? Am J Infect Control. 2011; 39(5):379-81.

9. Saxena S, Singh T, Agarwal H, et al. Bacterial colonization of rings and cell phones carried by health-care providers: are these mobile bacterial zoos in the hospital? Trop Doct. 2011; 41(2):116-8.

10. Malacarne P, Pini S, De Feo N. Relationship between pathogenic and colonizing microorganisms detected in intensive care unit patients and in their family members and visitors. Infect Control Hosp Epidemiol. 2008; 29(7): 679-81.

11. Lecat P, Cropp E, McCord G, Haller NA. Ethanolbased cleanser versus isopropyl alcohol to decontaminate stethoscopes. Am J Infect Control. 2009; 37(3): 241-3.

12. Arévalo H, Cruz R, Palomino F, Fernández F, Guzmán E, Melgar R. Aplicación de un programa de control de infecciones intrahospitalarias en establecimientos de salud de la región San Martín, Perú. Rev peru med exp salud publica. 2003; 20(2):84-91.

1 Facultad de Salud Pública y Administración “Carlos Vidal Layseca”. Universidad Peruana Cayetano Heredia. Lima, Perú.

a Profesor principal 